\title{
Primary knee joint arthroplasty trends at the Vreden National Medical Research Centre for Traumatology and Orthopedics compared with other national joint replacement registries. Is our way similar?
}

\author{
A.S. Fil ${ }^{1}$, V.N. Tarakanov ${ }^{1,3}$, T.A. Kulyaba ${ }^{1}$, N.N. Kornilov ${ }^{1,2}$ \\ ${ }^{1}$ Vreden National Medical Research Center of Traumatology and Orthopedics, Saint Petersburg, Russian Federation \\ ${ }^{2}$ North-Western State Medical University named after I.I. Mechnikov, Saint Petersburg, Russian Federation \\ ${ }^{3}$ Saint-Petersburg State University, Saint-Petersburg, Russian Federation
}

\begin{abstract}
Introduction Total joint replacement is one of the most effective and successful surgical interventions. Regular monitoring of these surgical interventions is essential and may serve as a system for early detection of defective prosthesis designs or techniques resulting in the complication rate which exceeds the estimated level. The ideal way to conduct this monitoring is a registry of joint replacements. Purpose Assessment of the structure of primary knee joint arthroplasty at the Federal State Budgetary Institution Vreden National Medical Research Centre for Traumatology and Orthopaedics named and it's comparative analysis with the data from leading foreign registers to improve the work of orthopaedic surgeons, traumatologists and healthcare organizers by optimizing the surgical tactics in the specialized treatment of patients. Methods The authors reviewed the annual reports published by national registers of knee replacements and compared them with the data of the registry of the Vreden National Medical Research Centre for Traumatology and Orthopaedics to make conclusions that would be relevant to current orthopaedic practice. Results Several results of the survey demonstrate the most significant or unexpected conclusions as according to the registry. These include an extremely large gender imbalance and obesity as two thirds of the patients were overweight. The number of patients with tumors and rheumatological diseases in the structure of knee replacements decreased considerably in the recent years. Designs and types of implants used, patellar resurfacing in arthroplasty, time of surgical intervention and options for postoperative administrations of antibiotics at the Vreden Centre are consistent with general European trends in knee arthroplasty. Conclusions The number of primary knee replacements (including unicompartment replacements) has been increasing annually. The patients admitted for primary knee replacement are statistically very similar to patient population from other countries. The main differences are associated with an earlier age at which arthroplasty is performed, an extreme gender imbalance and a relatively low number of patellar resurfacing in primary knee replacement. The problem of overweight among the population leads to an increased number of knee replacements, complications and lower implant survival rate.
\end{abstract}

Keywords: knee joint, total arthroplasty, unicompartmental knee arthroplasty, registry, national registry, osteoarthritis

\section{INTRODUCTION}

The centre for large joint replacement has been functioning at the Vreden National Medical Research Cenre for Traumatology and Orthopaedics since 1991. For three decades, the arthroplasty practice has turned for orthopadic surgeons from solitary cases to an every-day routine. The growth in the number of joint replacements, mainly knee and hip arthroplasties, requires their registration, that is to keep a registry for the analysis of such a great volume of data $[1,2]$. At the beginning, the registry was maintained on paper carriers (hip replacements) but since 2011 the electronic maintanance has been executed for hip and knee replacements [1]. Being constantly improved and supplemented, the registry contains data on 27,798 hip replcements and 27,906 knee replacements from 2011 to 2019. Despite a small term, and also thanks to targeted financial support of such operations, we dispose of a sufficient clinical and statistical material that enables to make evaluations of the tendencies in arthroplasty performance existing not only at our cenre but also in Russia [3-11].

\section{MATERIAL AND METHODS}

Data from the registries of Vreden NMRC for TO and national registries of Sweden, Australia, New Zealand, Norway, Japan, USA, Canada, England/ Wales were studied. Data on knee arthroplasty included epidemiological information, types of arthroplasty, types of implant components and their connection, patellar resurfacing, unicompartmental and revision knee joint arthroplasty. Registry and demographic information was presented with the use of descriptive statistics.

\section{RESULTS}

According to the Vreden NMRC for TO registry, in the period from 2011 to 2019 , the portion of

primary knee joint arthroplasties in the total of 27906 operations was $92.3 \%(n=25,759)$, and $7.7 \%$ were

[ Fil A.S., Tarakanov V.N., Kulyaba T.A., Kornilov N.N. Primary knee joint arthroplasty trends at the Vreden National Medical Research Centre for Traumatology and Orthopedics compared with other national joint replacement registries. Is our way similar? Genij Ortopedii, 2020, vol. 26, no 4, pp. 476-483. DOI 10.18019/1028-4427-2020-26-4-476-483 
revisions $(n=2,147)$ (Fig. 1). The number of primary knee joint replacement per year grew almost twofold, from 1,678 in 2011 to 3,730 in 2019.

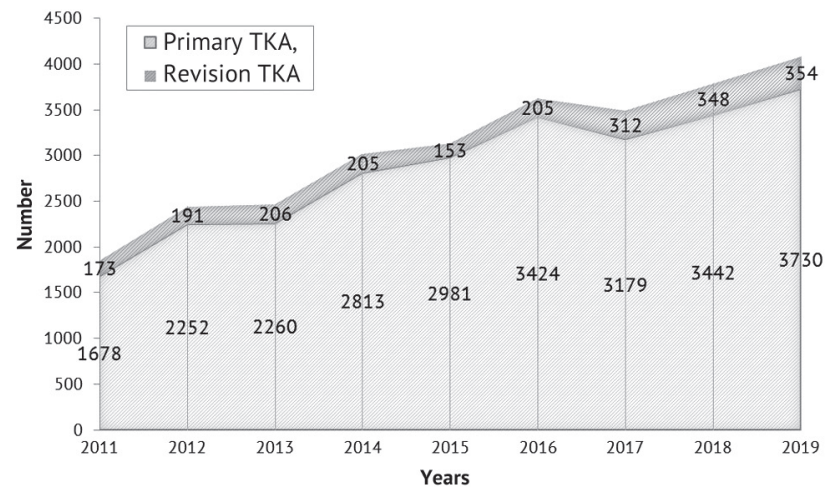

Fig. 1 Annual numbers of primary knee joint arthroplasties and number of revisions performed at Vreden NMRC for TO in 2011-2019

Minimal age of patients was 18 years and the maximal was 92 years, the mean age increased from 61.68 years in 2011 to 64.3 years in 2019 (Table 1).

The male to female relative ratio was 15.4 and $84.6 \%$, respectively (Fig. 2).

The main age groups were in the range of 55-64 and 65-74 years and these were two thirds of the total of patients. The smallest age group was persons in the age of 85 years and older, only $0.3 \%$ (Fig. 3).

The so called "epidemics of obesity" has been much discussed lately. According to the ministry of health of the Russian Federation, the number of patients diagnosed with obesity has grown by one third in the period from 2011 to 2017 [12]. Similar data were obtained by the analysis of the registry at NMRC for TO. Thus, the number of patients with the body mass index (BMI) of 30-39.9 and over 40 increased from $44.3 \%$ and $5.7 \%$ in 2011 to $55.3 \%$ and $10.1 \%$ in 2019 , respectively (Fig. 4).

The main nosological group according to the registry is the group of osteoarthrosis, including idiopathic, posttraumatic and other secondary arthroses. An annual growth of this group cases was revealed, from $90.7 \%$ in 2011 to $96.8 \%$ in 2019 . On the contrary, decrease was noted in the group of rheumatoid arthritis and systemic diseases from $8.1 \%$ in 2011 to $2.8 \%$ in 2019 which may be related to the general growth of osteoarthritis incidence and development of conservative treatment methods of systemic diseases and consequently to the decrease in the necessity of radical surgical treatment (Fig. 5).

Table 1

Patients' age at primary knee joint arthroplasty at Vreden NMRC for TO in 2011-2019

\begin{tabular}{|l|c|c|c|c|c|c|c|c|c|}
\hline & \multicolumn{9}{|c|}{ Age, years } \\
\hline Year & 2011 & 2012 & 2013 & 2014 & 2015 & 2016 & 2017 & 2018 & 2019 \\
\hline Minimal & 21 & 19 & 19 & 19 & 22 & 19 & 18 & 23 & 21 \\
\hline Maximal & 89 & 88 & 91 & 92 & 92 & 89 & 88 & 91 & 88 \\
\hline Mean & 61.68 & 63.23 & 63.5 & 63.64 & 63.3 & 64.5 & 64.03 & 64.56 & 64.3 \\
\hline SD* & 10.98 & 10.01 & 10.1 & 9.36 & 9.4 & 9.4 & 9.06 & 8.96 & 9.5 \\
\hline
\end{tabular}

*SD - standard deviation

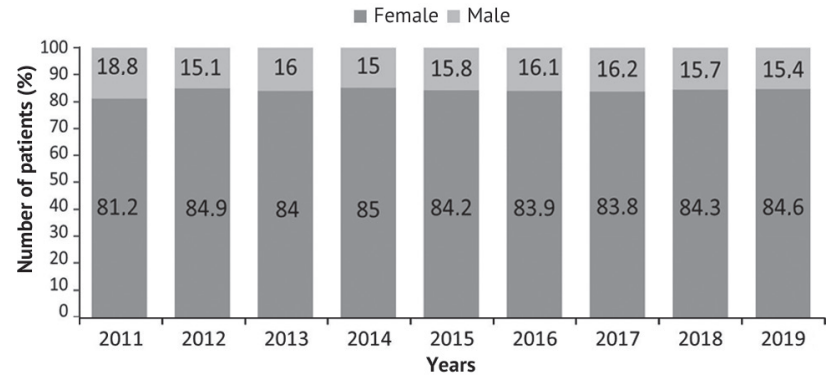

Fig. 2 Patients' gender at primary knee joint arthroplasty at Vreden NMRC for TO in 2011-2019

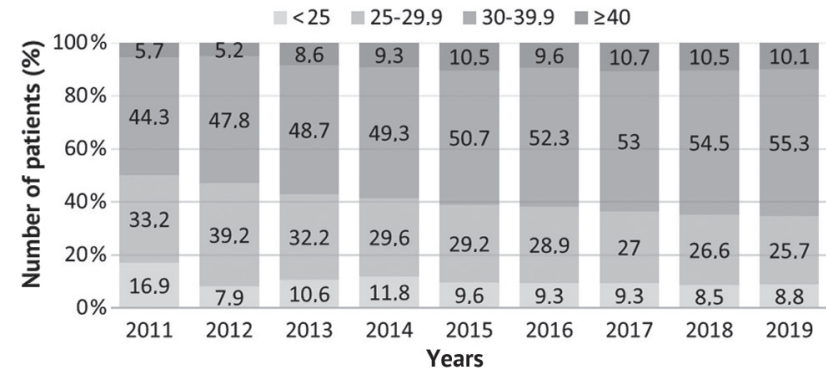

Fig. 4 Body mass index in patients with primary knee arthroplasty at Vreden NMRC for TO in 2011-2019

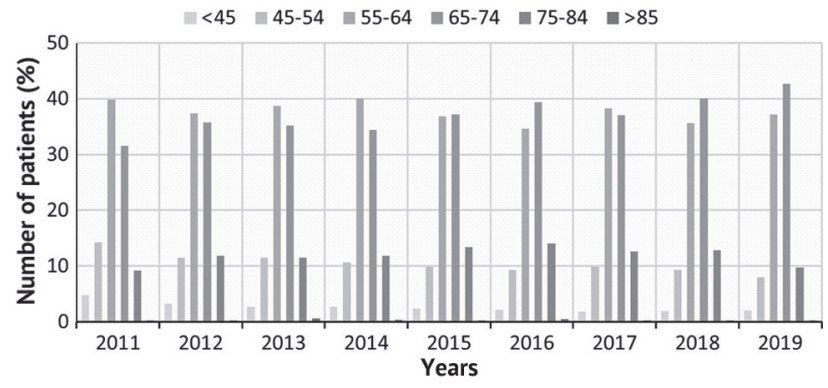

Fig. 3 Age groups of knee arthroplasty patients at Vreden NMRC for TO in 2011-2019

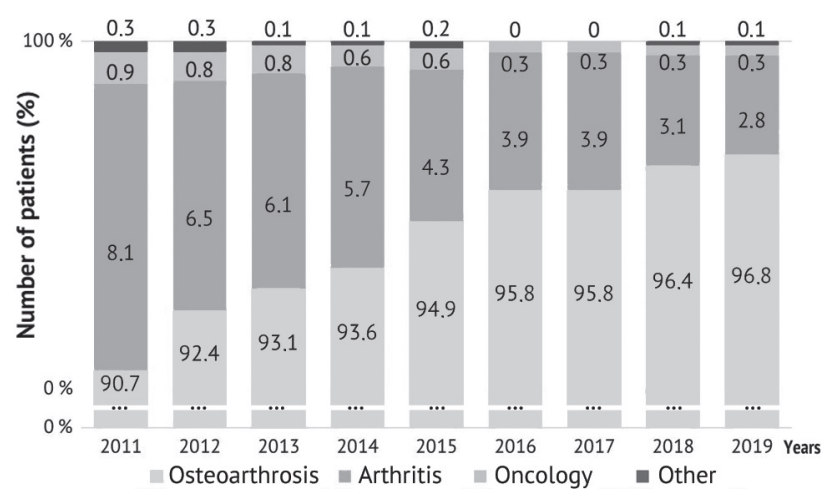

Fig. 5 Nosological groups of patients at primary knee arthroplasty at Vreden NMRC for TO in 2011-2019 
The most frequent type of surgical interventions at Vreden NMRC for TO is total knee arthroplasty without patellar resurfacing that made $90.8 \%$ of cases in 2019. Patellar resurfacing in primary knee arthroplasty remained at the same level in the period studied, about $2.8 \%$. A significant increase was in the number of unicompartmental knee arthroplasties at NMRC for TO from $0.3 \%$ in 2011 to $6.4 \%$ in 2019. Also, in 2019, two replacements of the patellofemoral joint were performed (Fig. 6).

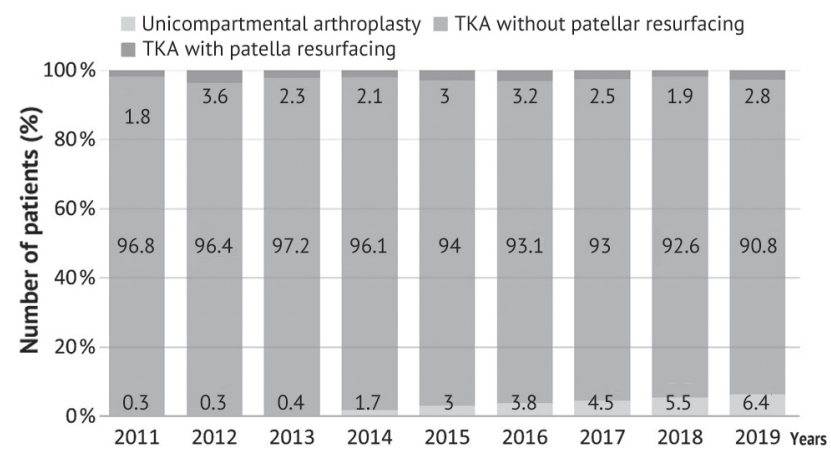

Fig. 6 Types of primary knee arthroplasty performed at Vreden NMRC for TO in 2011-2019

In 2011-2013, the duration of more than $70 \%$ of knee joint replacement operations was 1.5-3.0 hours. However, in 2014 the duration of interventions changed and the operations of 90-180 minutes constituted 53.6\% and continued to decrease to $36.1 \%$ in 2019 while interventions lasting less than 90 minutes made $63.4 \%$. Also, the number of operations that took more than 180 minutes to perform reduced from $2.9 \%$ in 2011 to $0.5 \%$ in 2019. This tendency was due to accumulation of surgeons' experience and perfection of anesthesia provision of operations at Vreden NMRC for TO. The use of the preparations from the group of fibrinolysis inhibitors and control of arterial hypotension provided a considerable reduction in blood loss, facilitated the work of surgeons and decreased the time of interventions (Fig. 7).

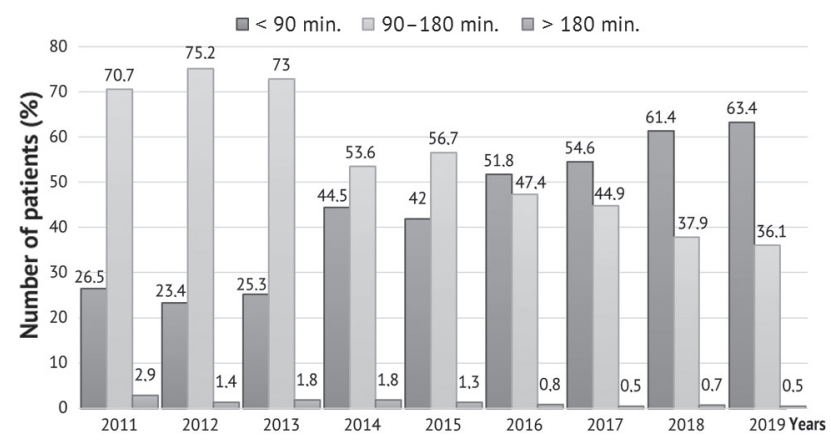

Fig. 7 Comparison of primary knee arthroplasty intervention duration at Vreden NMRC for TO in 2011-2019

The number of patients with intraoperative blood loss of 500-1000 ml decreased as compared with the group of patients with blood loss of less than $500 \mathrm{ml}$ from $77 \%$ in 2011 to $97.1 \%$ in 2019 . The relative number of operations with the blood loss of more than $1,000 \mathrm{ml}$ at primary knee arthroplasty decreased considerably in the period of 2011-2019 (Fig. 8).

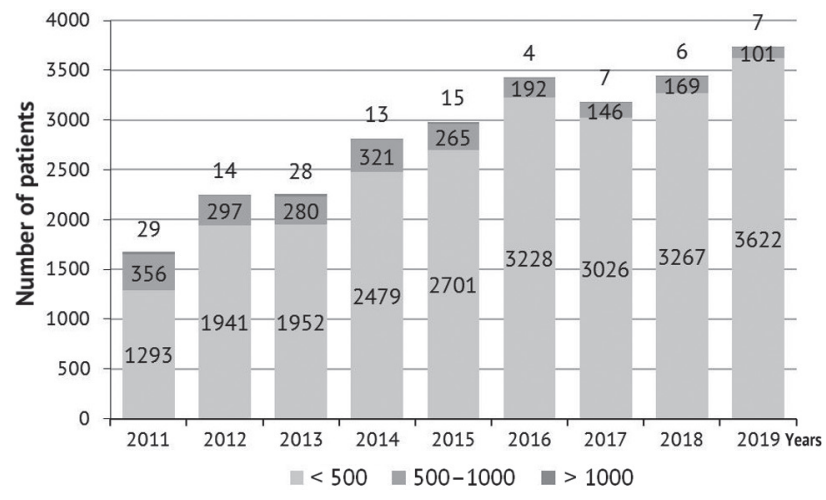

Fig. 8 Blood loss volumes at knee arthroplasty at Vreden NMRC for TO in 2011-2019

Table 2 presents implant designs used at the Vreden NMRC for TO. Zimmer NexGen implants took a lead over the former leader J\&J DePuy PFC Sigma in 2014. The implants S\&N Anthem have taken the third place and the number of arthroplasties with this implant has been steadily growing since 2017. Nevertheless, the appearance of other implant designs should be noted along with a considerable growth of implants used for unicondylar arthroplasty.

Unconstrained cruciate-retaining (CR) prostheses were most frequently implanted. Their maximum number was implanted in 2016 and made $74.7 \%$ but decreased to $64.4 \%$ in 2019 . There is a stable tendency to decrease in the implants with posterior stabilization (PS) from $30.4 \%$ in 2011 to the minimum of $15.9 \%$ in 2018. However, in 2019 the number of implanted PS prostheses grew to $20.2 \%$. The implants of Deep Dish group have been installed in an insufficient number of cases and made $4.6 \%$ in 2019 (at NMRC for TO this group has been represented at present by designs of J\&J DePuy LCS and Microport Wright Advance) (Table 3).

Tibial components of All Poly types were used in $7.2 \%$ of cases in 2019. A sufficiently high portion (7.5\%) of implants with a mobile polyethylene insert can be explained by inclusion of unicompartmental prosthesis Biomet Oxford into this group. However, reduction in the number of implanted prostheses with a non-modular tibial component should be noted (Monoblock and All Poly) (Fig. 9).

The absolute number of knee joint implants was fixed with bone cement in 2019 (more than $99 \%$ ). The main type of the bone cement used at the Vreden NMRC for TO was without antibiotics $(73.2 \%)$ in 2019.

Duration of antibiotic therapy (usually 5 to 7 days) decreased due to a three-day antibacterial prophylaxis which cases increased from $4.9 \%$ in 2011 to $73.8 \%$ in 2019 (Fig. 10). 
Implant designs used for primary knee arthroplasty at Vreden NMRC for TO in 2011-2019

Table 2

\begin{tabular}{|c|c|c|c|c|c|c|c|c|c|c|c|c|c|c|c|c|c|c|}
\hline \multirow{3}{*}{ Design } & \multicolumn{18}{|c|}{ Year } \\
\hline & \multicolumn{2}{|c|}{2011} & \multicolumn{2}{|c|}{2012} & \multicolumn{2}{|c|}{2013} & \multicolumn{2}{|c|}{2014} & \multicolumn{2}{|c|}{2015} & \multicolumn{2}{|c|}{2016} & \multicolumn{2}{|c|}{2017} & \multicolumn{2}{|c|}{2018} & \multicolumn{2}{|c|}{2019} \\
\hline & $\mathrm{N}$ & $\%$ & $\mathrm{~N}$ & $\%$ & $\mathrm{~N}$ & $\%$ & $\mathrm{~N}$ & $\%$ & $\mathrm{~N}$ & $\%$ & $\mathrm{~N}$ & $\%$ & $\mathrm{~N}$ & $\%$ & $\mathrm{~N}$ & $\%$ & $\mathrm{~N}$ & $\%$ \\
\hline $\begin{array}{l}\text { NexGen } \\
\text { Zimmer }\end{array}$ & 441 & 26.4 & 550 & 24.5 & 646 & 28.6 & 803 & 28.5 & 1072 & 36.0 & 1270 & 37.1 & 1173 & 36.9 & 1097 & 31.9 & 1114 & 29.9 \\
\hline $\begin{array}{l}\text { PFC Sigma } \\
\text { DePuy J\&J }\end{array}$ & 696 & 41.7 & 950 & 42.3 & 795 & 35.2 & 770 & 27.3 & 284 & 9.5 & 613 & 17.9 & 662 & 20.8 & 502 & 14.6 & 522 & 14.0 \\
\hline Anthem S\&N & 0 & 0.0 & 0 & 0.0 & 0 & 0.0 & 0 & 0.0 & 0 & 0.0 & 0 & 0.0 & 69 & 2.2 & 300 & 8.7 & 477 & 12.8 \\
\hline AGC Biomet & 398 & 23.8 & 397 & 17.7 & 372 & 16.5 & 356 & 12.6 & 544 & 18.2 & 425 & 12.4 & 293 & 9.2 & 374 & 10.9 & 342 & 9.2 \\
\hline $\begin{array}{l}\text { Columbus } \\
\text { Aesculap }\end{array}$ & 65 & 3.9 & 239 & 10.6 & 278 & 12.3 & 314 & 11.2 & 365 & 12.2 & 447 & 13.1 & 310 & 9.8 & 262 & 7.6 & 240 & 6.4 \\
\hline $\begin{array}{l}\text { Triathlon } \\
\text { Stryker }\end{array}$ & 0 & 0.0 & 0 & 0.0 & 0 & 0.0 & 0 & 0.0 & 0 & 0.0 & 0 & 0.0 & 75 & 2.4 & 290 & 8.4 & 239 & 6.4 \\
\hline $\begin{array}{l}\text { Oxford PK } \\
\text { Biomet }\end{array}$ & 7 & 0.4 & 2 & 0.1 & 8 & 0.4 & 33 & 1.2 & 75 & 2.5 & 115 & 3.4 & 127 & 4.0 & 161 & 4.7 & 220 & 5.9 \\
\hline $\begin{array}{l}\text { Microport } \\
\text { Wright } \\
\text { Advance }\end{array}$ & 0 & 0.0 & 0 & 0.0 & 0 & 0.0 & 0 & 0.0 & 0 & 0.0 & 0 & 0.0 & 0 & 0.0 & 61 & 1.8 & 160 & 4.3 \\
\hline $\begin{array}{l}\text { Scorpio NRG } \\
\text { Stryker }\end{array}$ & 0 & 0.0 & 0 & 0.0 & 2 & 0.1 & 153 & 5.4 & 343 & 11.5 & 295 & 8.6 & 268 & 8.4 & 139 & 4.0 & 123 & 3.3 \\
\hline $\begin{array}{l}\text { Genesis II } \\
\text { S\&N }\end{array}$ & 0 & 0.0 & 0 & 0.0 & 4 & 0.2 & 108 & 3.8 & 129 & 4.3 & 110 & 3.2 & 86 & 2.7 & 90 & 2.6 & 122 & 3.3 \\
\hline $\begin{array}{l}\text { Vanguard } \\
\text { Biomet }\end{array}$ & 0 & 0.0 & 0 & 0.0 & 0 & 0.0 & 0 & 0.0 & 82 & 2.8 & 89 & 2.6 & 61 & 1.9 & 54 & 1.6 & 74 & 2.0 \\
\hline $\begin{array}{l}\text { Freedom } \\
\text { MaxxMed }\end{array}$ & 0 & 0.0 & 0 & 0.0 & 0 & 0.0 & 0 & 0.0 & 0 & 0.0 & 0 & 0.0 & 0 & 0.0 & 38 & 1.1 & 43 & 1.2 \\
\hline Uni S\&N & 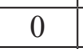 & 0.0 & 0 & 0.0 & 1 & 0.0 & 6 & 0.2 & 8 & 0.3 & 14 & 0.4 & 16 & 0.5 & 26 & 0.8 & 18 & 0.5 \\
\hline $\begin{array}{l}\text { LCS DePuy } \\
\text { J\&J }\end{array}$ & 39 & 2.3 & 45 & 2.0 & 65 & 2.9 & 202 & 7.2 & 4 & 0.1 & 24 & 0.7 & 22 & 0.7 & 27 & 0.8 & 12 & 0.3 \\
\hline Biomet DA & 0 & 0.0 & 0 & 0.0 & 10 & 0.4 & 11 & 0.4 & 1 & 0.0 & 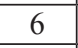 & 0.2 & 0 & 0.0 & 3 & 0.1 & 7 & 0.2 \\
\hline Biomet OSS & 13 & 0.8 & 15 & 0.7 & 19 & 0.8 & 11 & 0.4 & 9 & 0.3 & 7 & 0.2 & 5 & 0.2 & 6 & 0.2 & 3 & 0.1 \\
\hline $\begin{array}{l}\text { Balansys } \\
\text { Manthys }\end{array}$ & 11 & 0.7 & 47 & 2.1 & 60 & 2.7 & 37 & 1.3 & 49 & 1.6 & 0 & 0.0 & 0 & 0.0 & 0 & 0.0 & 0 & 0.0 \\
\hline Others & 0 & 0.0 & 0 & 0.0 & 0 & 0.0 & 12 & 0.4 & 16 & 0.5 & 3 & 0.3 & 12 & 0.4 & 12 & 0.3 & 14 & 0.4 \\
\hline Total & 1670 & 100 & 2245 & 100 & 2260 & 100 & 2816 & 100 & 2981 & 100 & 3424 & 100 & 3179 & 100 & 3442 & 100 & 3730 & 100 \\
\hline
\end{tabular}

Table 3

Prosthesis designs according to their constrainment type used for primary knee arthroplasty at Vreden NMRC for TO in 2011-2019

\begin{tabular}{|c|c|c|c|c|c|c|c|c|c|c|c|c|c|c|c|c|c|c|}
\hline \multirow{3}{*}{ Implants } & \multicolumn{18}{|c|}{ Year } \\
\hline & \multicolumn{2}{|c|}{2011} & \multicolumn{2}{|c|}{2012} & \multicolumn{2}{|c|}{2013} & \multicolumn{2}{|c|}{2014} & \multicolumn{2}{|c|}{2015} & \multicolumn{2}{|c|}{2016} & \multicolumn{2}{|c|}{2017} & \multicolumn{2}{|c|}{2018} & \multicolumn{2}{|c|}{2019} \\
\hline & $\mathrm{N}$ & $\%$ & $\mathrm{~N}$ & $\%$ & $\mathrm{~N}$ & $\%$ & $\mathrm{~N}$ & $\%$ & $\mathrm{~N}$ & $\%$ & $\mathrm{~N}$ & $\%$ & $\mathrm{~N}$ & $\%$ & $\mathrm{~N}$ & $\%$ & $\mathrm{~N}$ & $\%$ \\
\hline 4.5 & 188 & 5.5 & 239 & 6.4 & 9 & 0,4 & 39 & 1,4 & 83 & 2,8 & 129 & 3,9 & 143 & 4,5 & 188 & 5,5 & 239 & 6,4 \\
\hline $\mathrm{CR}$ & 1013 & 60.4 & 1308 & 58.0 & 1556 & 68.8 & 1816 & 64.8 & 2088 & 70.2 & 2461 & 74.7 & 2233 & 70.2 & 2349 & 68.2 & 2403 & 64.4 \\
\hline PS & 510 & 30.4 & 768 & 34.1 & 475 & 21.0 & 478 & 17.1 & 632 & 21.3 & 625 & 19.0 & 575 & 18.1 & 548 & 15.9 & 752 & 20.2 \\
\hline Dee & 45 & 2.7 & 70 & 3.1 & 126 & 5.6 & 236 & 8.4 & 55 & 1.8 & 113 & 3.4 & 22 & 0.7 & 89 & 2.6 & 172 & 4.6 \\
\hline $\mathrm{VVC}^{\prime}$ & 46 & 2.7 & 52 & 2.3 & 58 & 2.6 & 79 & 2.8 & 88 & 3.0 & 70 & 2.1 & 90 & 2.8 & 86 & 2.5 & 100 & 2.7 \\
\hline Hing & 3 & 1.8 & 23 & 1.0 & 33 & 1.5 & 38 & 1.4 & 23 & 0.8 & 20 & 0.6 & 34 & 1.1 & 34 & 1.0 & 52 & 1.4 \\
\hline Incom & 26 & 1.5 & 31 & 1.4 & 3 & 0.1 & 117 & 4.2 & 5 & 0.2 & 6 & 0.2 & 82 & 2.6 & 148 & 4.3 & 10 & 0.3 \\
\hline Total & 1678 & 100 & 2254 & 100 & 2260 & 100 & 2803 & 100 & \begin{tabular}{|l|l|}
2974 \\
\end{tabular} & 100 & 3295 & 100 & \begin{tabular}{|l|}
3179 \\
\end{tabular} & 100 & 3442 & 100 & \begin{tabular}{|l|}
3730 \\
\end{tabular} & 100 \\
\hline
\end{tabular}

* - UNI - Unicondylar/Unicompartmental; ** - Deep Dish - ultracongruent implants ; *** - VVC - Varus-valgus constrained

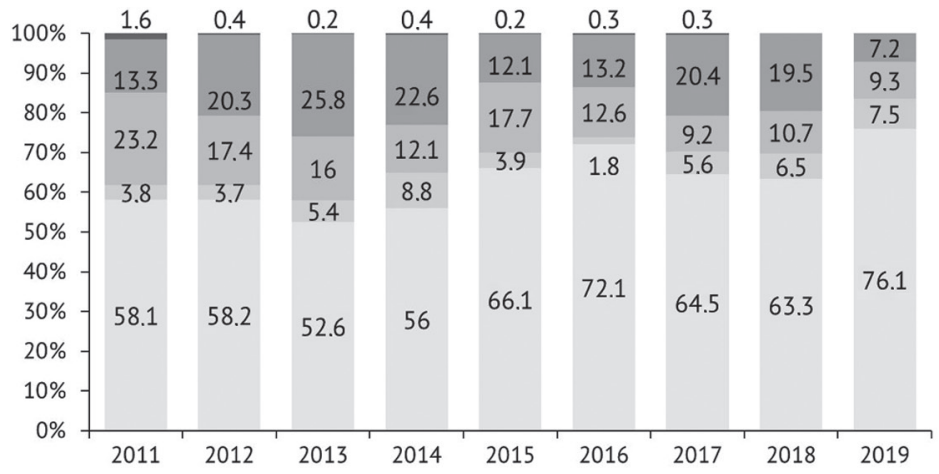

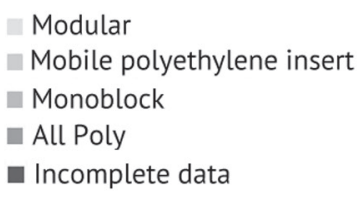

Fig. 9 Distribution of implants for primary knee arthroplasty at NMRC for TO in 2011-2019 according to the type of tibial components 


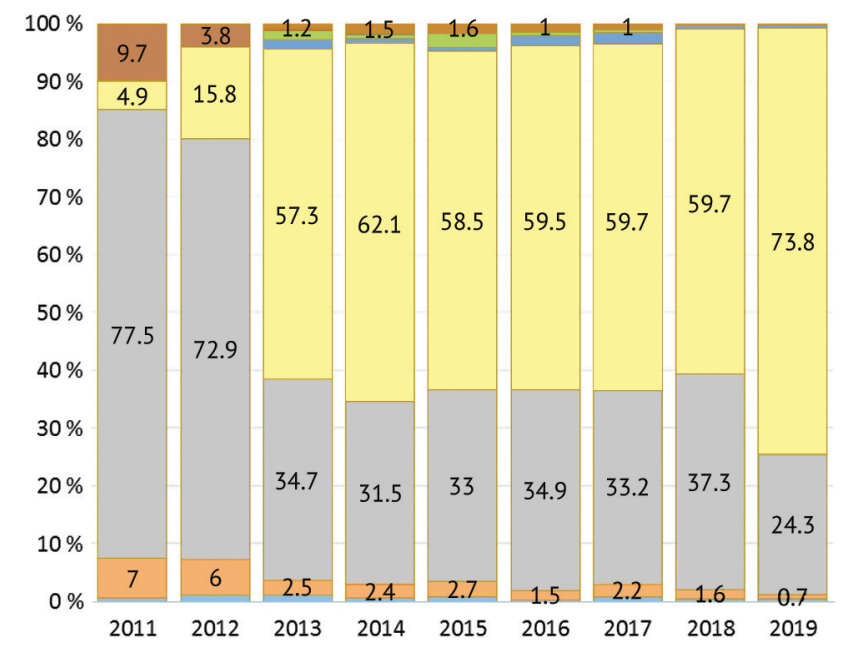

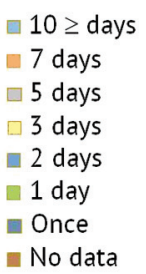

Fig. 10 Distribution of patients according to antibacterial therapy after knee joint arthroplasty at Vreden NMRC for TO in 2011-2019

\section{DISCUSSION}

An annual increase in the number of knee arthroplasties was shown in the regisries of Australia (increase by $1.2 \%$ in 2018 as compared with 2017), Sweden (growth by $3.3 \%$ in 2018) [3,6]. The number of such interventions performed in England/ Wales in 2018 was similar to 2017 [5]. But in Russia it grew by $7.7 \%$ in 2019 when compared with 2018 . This gap may be associated with the fact that the peak of knee arthroplasty cases has not been reached in Russia yet and the increase in the number of such joint replacements, as estimated, will grow.

According to the Australian registry, primary arthroplasties constituted $92.0 \%$ in the period from 1999 to 2018; in New Zealand it was $92.75 \%$ in the same period; in Canada it was $93 \%$ in 2017-2018; in Norway $92.3 \%$; and the USA registry reported $90 \%$ for the period from 2012 to 2018 [3, 7, 9-11]. The Swedish registry of knee arthroplasties reports $92.3 \%$ of primary interventions in 2018 [6]. The Swiss registry recorded $88 \%$ of primary arthroplasties in 2018 [4]. Thus, we should point to a high level of correlation between the data reported by the Vreden NMRC for TO (92.3\%) and the general world orthopaedic tendency.

The majority of primary knee arthroplasties in England and Wales were performed in females (56.7 \%) in 2018. In Australia and New Zealand the portion of arthroplasties in females was 55.2 and $51.6 \%$, respectively $[3,7]$. The Swedish and Norwegian registries present the male/female ratio of primary knee arthroplasties as 43.89:56.11 \% and 37.5:62.5\%, respectively $[6,11]$. In Switzerland the female/male arthroplasty ratio is 60.4 to $39.6 \%$, in the USA -66 to $34 \%[4,10]$. In Russia, the female/male ratio of knee arthroplasties is 84.6 to $15.4 \%$, which correponds to the data of the Japanese registry ( 81 to $19 \%$ ) (Fig. 11) [8]. Large discrepancy in male and female population in Russia and Japan might be explained by a deep demographic crisis these countries suffer in the last 30 to 40 years: low birth rate, high mortality of working age population, increase in the average life expectancy, especially in women. Judging from this demographic tendency, one could expect a further gender imbalance in the structure of knee joint arthroplasties [12, 13].

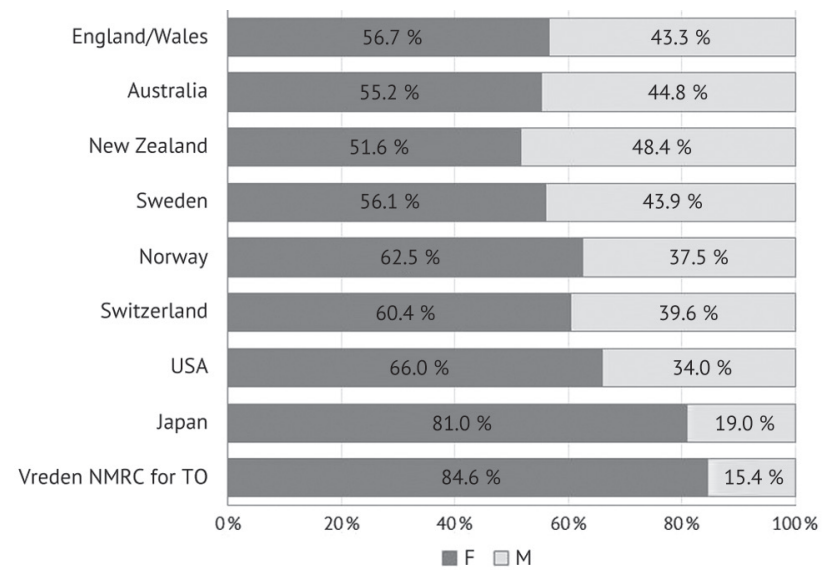

Fig. 11 Comparative gender characteristics of patients at primary knee arthroplasty according to foreign registries and Vreden NMRC for TO registry

The average age of patients undergoing primary knee joint arthroplasty in Great Britain, Switzerland, Australia, Sweden, and New Zealand was 68-70 years and had a tendency to grow what is higher than the average age according to the NMRC for TO registry (64-65 years) and the USA registry (67 years) [3-11]. In Australia, there was a decrease in the number of patients of the age group of 75 to 84 years old from $29.5 \%$ in 2003 to $21.9 \%$ in 2018; the portion of patients younger than 55 years old was small $(6.5 \%)$ in 2018, and this percentage has not changed much since 2003 [3]. The availability of non-medication and medication therapy for gonarthrosis which might be used in its early stage to delay its development would have an impact on the age factor and necessity for arthroplasty and would approximate the age of patients in Russia to the one of these countries of the world.

Gonarthrosis is the most frequent cause $(97.4 \%)$ leading to the necessity of arthroplasty in England/ Wales, $96.73 \%$ in Sweden and $97.7 \%$ in Australia in $2018[3,5,6]$. The data of the New Zealand registry 
for the period 1999-2018 were: gonarthrosis $94.8 \%$, rheumatoid arthritis $-2.1 \%$, post-traumatic gonarthrosis as complication of fractures - 1.0\% [7]. The registry of Switzerland reported the following data: gonarthrosis - 96.2\%; osteonecrosis - $1.8 \%$; arthritis $0.9 \%$; infection $-0.2 \%$, other $1.4 \%$ [4]. These similar findings confirm the necessity to improve the diagnosis and treatment of gonarthrosis at its early stage.

The mean BMI at the Vreden NMRC for TO in the years studied was 32.8. According to the New Zealand registry it was 31.3 [7]. The incidence of overweight/ obesity varies in different ethnic populations, affecting $66.5 \%$ of the population of the Pacific region origin, $48.2 \%$ among maori, and $29.1 \%$ among the settlers of the European origin. Asian origin population develops obesity in only $13.8 \%$. Adult population residing in economically undeveloped countries has obesity 1.6 times more frequent than the residents of more developed regions [15].

Cemented techniques of primary knee arthroplasty were used in $86.1 \%$ of cases in Sweden, and cementless in $12.3 \%$, hybrid fixation was used in $0.5 \%$ of cases [6]. Despite better results shown for biointegration and operation time reduction, cementless implants have not been so widely used due to their higher costs.

According to the Australian registry, the number of patellar resurfacing in knee replacement grew from $41 \%$ in 2005 to $69.1 \%$ in 2018 [3]. At the Vreden NMRC for TO, patellar resurfacing in primary knee arthroplasty was performed in $2.8 \%$ of cases. Low rates of primary knee cup resurfacing at our centre correspond to the European tendencies. Thus, in 2018 patellar resurfacing was used in $2.9 \%$ of cases as reported by the Swedish registry and in $7.3 \%$ by the Norwegian registry $[6,11]$. The difference might be explained by the fact that for reduction of risks of revision arthroplasty the manufacturers may recommend the performance of arthroplasty with patellar resurfacing or not, depending on the implant design.

Table 4 presents the most used implant designs. The registries of New Zealand, Sweden and our centre report that ten most implanted prostheses make $95 \%$ from the total $[6,7]$. Differences in the data with the

Australian registry may be explained by a different system of implant design registration [3].

Fully polyethylene tibial components were used in $1.36 \%$ of cases in England/Wales in 2018 [5].

As for unicompartmental arthroplasties, the latest data in England/Wales and Sweden have reported the growth in their number, up to 11.1 and $9.3 \%$, respectively $[5,6]$. In Switzerland and Norway, the number of unicompartmental arthroplasties is at stable level and was $15.1 \%$ and $14.5 \%$ in 2018 , respectively $[4,11]$. In Australia, the number of partial knee arthroplasties decreased from 14.5 in 2004 to $4.2 \%$ in 2014 , but in the past four years their growth was noted and reached $5.8 \%$ in 2018 [3]. An annual increase in the number of unicompartmental arthroplasties has been observed at the Vreden centre and was $6.4 \%$ from the total of primary knee joint replacements in 2019. The potential for its growing number in the future has no doubts as partial arthroplasty has a number of advantages over the total knee joint replacement. Significant merits are lower rates of periprothetic infection and life-threatening complications of the cardiovascular system (heart and brain strokes, venous thromboembolism), a two-fold reduction in the rehabilitation period and better functional outcomes (deeper flexion and the phenomenon of the "forgotten" knee) along with a simpler technical performance and loayal costs of revisions if necessary. The experience of the surgeons in Norway and Switzerland confirm that partial replacement of one of the knee joint compartments may be indicated for every seventh patient that needs arthroplasty. Lower rates of implant survival after partial arthroplasty as compared with the total replacement, what has been reflected in the national registries, are associated with a number of factors among which the accuracy of surgical performance and component positioning are the key ones $(70 \%$ of re-operations happen in the first five years after the intervention), a longer learning curve as well as simplicity of revision that requires standard total implants in the majority of cases.

Table 4

Most implanted prosthesis designs in primary knee arthroplasty according to the national registries as opposed to Vreden NMRC for TO

\begin{tabular}{|c|c|c|c|c|}
\hline & \multicolumn{4}{|c|}{ Data of registries on the prosthesis design implanted } \\
\hline & Australia & New Zealand & Sweden & Vreden NMRC for TO \\
\hline 1 & Triathlon CR $22 \%$ & Triathlon $35 \%$ & NexGen MBT $51.2 \%$. & NexGen $29.9 \%$ \\
\hline 2 & Nexgen CR Flex $10.3 \%$ & Attune $24 \%$ & PFC-MBT $19.6 \%$ & PFC Sigma $14.0 \%$ \\
\hline 3 & Persona $7.6 \%$ & Persona $15 \%$ & Triathlon $11.5 \%$ & Anthem $12.8 \%$ \\
\hline 4 & Attune CR $5.8 \%$ & Genesis II $5.4 \%$ & PFC-APT $7.6 \%$ & AGC $9.2 \%$ \\
\hline 5 & Nexgen LPS Flex $3.9 \%$ & Nexgen $4.3 \%$ & Genesis II $2.7 \%$ & Columbus $6.4 \%$ \\
\hline 6 & GMK Sphere Primary $3.8 \%$ & LCS $3.6 \%$ & Legion/Genesis II $2.5 \%$ & Triathlon $6.4 \%$ \\
\hline 7 & LCS CR $3.7 \%$ & PFC Sigma $3.5 \%$ & NexGen TM $1.6 \%$ & Oxford $5.9 \%$ \\
\hline 8 & Vanguard $3.5 \%$ & Balansys $1.8 \%$ & Persona $0.6 \%$ & Microport Wright Advance $4.3 \%$ \\
\hline 9 & Evolution $3.0 \%$ & Sigma $1.7 \%$ & Journey $0.4 \%$ & Scorpio NRG $3.3 \%$ \\
\hline 10 & Apex Knee CR $2.5 \%$ & Vanguard $1.6 \%$ & Vanguard $0.3 \%$; Attune $0.3 \%$ & Genesis II $3.3 \%$ \\
\hline
\end{tabular}


The analysis of the data in the registries has revealed several factors that should be discussed and that had an impact on the preparation of this study and its final version. One can note that not all the countries, the registries of which were chosen for the analysis, have been present in each of the parameters studied. And the reason is that these national registries have not been unified. The registries analysed in the work do not have even one parameter that could have been compared throughout all of them simultaneously (it also refers to demographic and biometrical data). A large layer of the data that might have had the information about the problems in the arthroplasty practice of some countries has been lost, and the attempts to collect the information in scientific studies or meta-analysis results in double work on gathering and processing of the material. A lot of hours could be saved if an additional line would appear in the reported form. Another problem is that national registries are maintained in national languages exclusively, like in Germany [16]. The national selfidentity of any nation should be respected but the translation of annual multi-page registries is too hard to complete. Thus, one cannot have a possibility to know the work of the colleagues from other countries. However, there is a way out which is to arrange correction of registry maintenance. Similar to the example with the change from a paper registry to an electronic one, some countries, instead of transferring a package of data to one registration centre, should better maintain digital platforms integrated with a medical information system of medical institutions and supported by state ministries [17, 18]. Similar system has been used at the Vreden NMRC for TO [19]. Such approach provides the work of the registry with minimum labour costs and time dedicated by the staff of the registry to its maintenance, provides everyday changes and arrangement of annual reports according to the pattern and translated into foreign languages for several days, not months. In relation to all above, the authors believe that the lack of a national registry of arthroplasties in Russia is a big drawback that needs to be considered by scientific societies and the medical authorities.

\section{CONCLUSIONS}

The following conclusions may be derived from the analysis of the registry at the Vreden NMRC for TO and data from the other national registries. There is a world tendency to a growth in the number of primary and revision knee joint arthroplasties. A "classical patient" from the countries mentioned above could be described as follows. It is an elderly woman with excessive body weight and gonarthrosis who will have an implantation of a total prosthesis of a modular type with preservation of the posterior cruciate ligament and cemented fixation of the implant components. The intervention would continue less than 90 minutes with a minimum blood loss $(<500 \mathrm{ml})$. She will be administered antibiotics for three post-operative days.

As opposed to the patient from other countries, a female patient admitted to NMRC for TO to undergo knee joint arthroplasty will have it at somewhat an earlier age and also will have a lesser probability of primary patellar resurfacing in total arthroplasty.

An annual increase in the number of primary arthroplasties implies the necessity to focus on the prevention, conservative treatment and low invasive interventions if indicated (unicondylar arthroplasty and corrective osteotomies). The potential of unicondylar replacement has not been realized well, and partly due to the myths about a short term of survival and high risks of revisions. A way out would be a joint work of scientific societies and implant manufacturers on training and propaganda of the surgical technique. It would be ideal that any orthopaedic surgeon that specializes in knee joint replacement masters unicondylar arthroplasty too.

The problem of excessive body weight that our population features has an impact not only on general health but also increases the likelihood of knee arthroplasties and the need to perform it at earlier age. It also leads to higher complication rate and lower survival of implants, and consequently, results in considerable financial expenditures for the healthcare system. Therefore, the struggle with obesity should be a national issue.

The growth in the number of PS implantations in the last three years of observation and the decrease in the number of tibial components of All Poly types and the proven higher survival of CR-implants and All Poly tibial components should make us revise these arthroplasty tendencies at our institution and requires further study.

The registry of the Vreden NMRC for TO, even with its positive features, is not a national one yet. Similar projects for the Russian medicine on the national scale are what is a need today and in the future.

\section{REFERENCES}

1. Chernyi A.Zh., Kuvakin V.I., Vorontsova T.N., Veber E.V., Kurchikov A.G. Sistema uchëta patsientov, nuzhdaiushchikhsia $\mathrm{v}$ endoprotezirovanii tazobedrennogo i kolennogo sustavov [Registration system for patients requiring the hip and the knee arthroplasty]. Vestnik Rossiiskoi Voenno-meditsinskoi Akademii, 2015, no. 4 (52), pp. 176-182. (in Russian)

2. Delaunay C. Registries in ortopaedics. Orthop. Traumatol. Surg. Res., 2015, vol. 101, no. 1 Suppl., pp. S69-S75. DOI: 10.1016/j. otsr.2014.06.029. 
3. AOA Annual Report. Australian Orthopaedic Association National Joint Replacement Registry. Ann. Report, 2019 , pp. 184-263.

4. Beck M., Christen B., Zdravkovic V., Brand C., Spoerri A. SIRIS Report 2019. Annual Report of the Swiss National Joint Registry, Hip and Knee, 2012-2018. Ann. Report, 2019, pp. 61-83. DOI: 10.13140/RG.2.2.15632.56323

5. Ben-Shlomo Y., Blom A., Boulton C., Brittain R., Clark E., Craig R., Dawson-Bowling S., Deere K., Esler C., Goldberg A., Gregson C., Howard P., Hunt L., Judge A., Lawrence S., Lenguerrand E., McCormack V., Newell C., Porteous M., Powers-Freeling L., Price A., Prieto-Alhambra D., Reed M., Rees J., Royall M., Sayers A., Stonadge J., Swanson M., Taylor D., Watts A., Whitehouse M., Wilkinson M., Wilton T., Young E. The National Joint Registry for England, Wales, Northern Ireland and Isle of Man. $16^{\text {th }}$ Ann. Report, 2019.

6. Robertsson O., Lidgren L., Sundberg M., W-Dahl A. The Swedish Knee Arthoplasty Register. Annual Report 2018. Ann. Report, 2018.

7. The New Zealand Joint Registry Nineteen Years Report (January 1999 - December 2018). Ann. Report, 2018.

8. 2016 Annual Report. The Japanese Society for Replacement Arthroplasty. The Japan Arthroplasty Register (TKA/UKA/PFA). Ann. Report, 2017.

9. Canadian Institute for Health Information. Hip and Knee Replacements in Canada, 2017-2018: Canadian Joint Replacement Registry. Annual Report. Ottawa, ON: CIHI, 2019, pp. 14-37.

10. American Joint Replacement Registry (AJRR): 2019 Annual Report. Rosemont, IL: American Academy of Orthopaedic Surgeons (AAOS), 2019. pp. 44-63. Available at: https://ortho.keckmedicine.org/pdfs/American-Joint-Replacement-Registry.pdf

11.Bergen H.F. Norwegian Arthroplasty Register, Norwegian Cruciate Ligament Register, Norwegian Hip Fracture Register, Norwegian Hip Fracture Register. Ann. Report, 2019.

12.Muramatsu N., Akiyama H. Japan: super-ageing society preparing for the future. Gerontologist, 2011, vol. 51, no. 4, pp. 425-432. DOI: 10.1093 /geront/gnr067

13.Sinelnikov A.B. Mozhno li srazu ostanovit ubyl naseleniia v Rossii? [Is it possible to stop the population decline in Russia immediately?]. Demograficheskie Issledovaniia. Nauchnyi Internet-Zhurnal, 2008, no. 7. (in Russian)

14.Polikarpov A.V., Aleksandrova G.A., Golubev N.A., Tiurina E.M., Oskov Iu.I., Shelepova E.A.; Ministerstvo Zdravookhraneniia RF, Departament Monitoringa, Analiza i Strategicheskogo Razvitiia Zdravookhraneniia, FGBU «Tsentralnyi Nauchno-Issledovatelskii Institut Organizatsii i Informatizatsii Zdravookhraneniia [the RF Ministry of Health, Department of Health Monitoring, Analysis and Strategic Development, FSBI "Central Scientific Research Institute of Organization and Informatization of Health Care"]. Zabolevaemost vzroslogo naseleniia Rossii v 2017 godu: statisticheskie materialy [Morbidity of the adult population of Russia in 2017: statistical materials]. M., 2018, part 3. (in Russian). Available at: https://miac58.ru/content/sbornik-osnovnyh-pokazateleydeyatelnosti-uchrezhdeniy-zdravoohraneniya-po-rf-za-2017-god (accessed 07.02.2020).

15. Annual Update of Key Results 2018/2019: New Zealand Health Survey, The New Zealand Ministry of Health. Available at: https:// www.health.govt.nz/nz-health-statistics/health-statistics-and-data-sets/obesity-statistics.

16.Grimberg A., Jansson V. (Wissenschaftlicher Direktor), Melsheimer O., Steinbrück A. Endoprothesenregister Deutschland (EPRD) [Arthroplasty Register of Germany (EPRD)]. Eine Initiative der Deutschen Gesellschaft für Orthopädie und Orthopädische Chirurgie e.V. Jahresbericht, 2019. (in German)

17.Puolakka T.J., Pajamäki K.J., Halonen P.J., Pulkkinen P.O., Paavolainen P., Nevalainen J.K. The Finnish Arthroplasty Register: report of the hip register. Acta Orthop. Scand., 2001, vol. 72, no. 5. pp. 433-441. DOI: 10.1080/000164701753532745. Available at: https://www.thl.fi/far/\#index (accessed: 06.06.2020).

18. Annual Report 2019. The Swedish Knee Arthroplasty Register Lund University Department of Clinical Sciences, Orthopedics Skåne University Hospital, Lund, Sweden. Ministry of Health and Social Affairs of Sweden. Available at: https://stat.myknee.se/?lang=en (accessed 07.06.2020).

19. Informatsionnaia sistema. Registr endoprotezirovaniia sustavov (RES) [Information System. Register of Joint Arthroplasty (RJA)]. FGBU "RNIITO im. R.R. Vredena" Minzdrava Rossii [FSBI "Russian Vreden Scientific Research Institute for Traumatology and Orthopaedics”]. (in Russian). Available at: https://res.rniito.org/index.php (accessed 07.06.2020).

Received: 06.07.2020

\section{Information about the authors:}

1. Alexey S. Fil, M.D., Ph.D.,

Vreden National Medical Research Center of Traumatology and Orthopedics, Saint Petersburg, Russian Federation,

Email: filalekse@yandex.ru

2. Vladimir N. Tarakanov, M.D.,

Vreden National Medical Research Center of Traumatology and Orthopedics, Saint Petersburg, Russian Federation, Saint-Petersburg State University, Saint-Petersburg, Russian Federation,

Email: Dr.Tarakanoff@gmail.com

3. Taras A. Kulyaba, M.D., Ph.D.,

Vreden National Medical Research Center of Traumatology and Orthopedics, Saint Petersburg, Russian Federation,

Vreden National Medical Research Center of Traumatology and Orthopedics, Saint Petersburg, Russian Federation,

Email: taraskuliaba@mail.ru

4. Nikolay N. Kornilov, M.D., Ph.D., Professor,

Vreden National Medical Research Center of Traumatology and Orthopedics, Saint Petersburg, Russian Federation,

North-Western State Medical University named after I.I. Mechnikov, Saint Petersburg, Russian Federation,

Email: drkornilov@hotmail.com 